\title{
Ultrasound Effectiveness of Steroid Injection for hand Psoriatic Dactylitis: Results from a Longitudinal Observational Study
}

\author{
Nicolò Girolimetto · Pierluigi Macchioni - Ilaria Tinazzi · Niccolò Possemato · \\ Luisa Costa - Vittoria Bascherini - Rosario Peluso - Giorgia Citriniti - Giulia Galletto • \\ Federica Martinis · Antonio Marchetta • Vincenzo Sabbatino · Marco Tasso • \\ Saverio Passavanti · Carlo Salvarani · Raffaele Scarpa · Francesco Caso
}

Received: May 24, 2021 / Accepted: September 29, 2021 / Published online: October 15, 2021

(C) The Author(s) 2021

\section{ABSTRACT}

Introduction: To assess clinical and ultrasound effectiveness of steroid injection (local treatment, LT) into the digital flexor tendon sheath for the treatment of psoriatic dactylitis compared to systemic treatment (ST) alone.

Methods: In this observational, multicentre, prospective study, 88 cases of symptomatic hand dactylitis were evaluated clinically and sonographically by high-frequency ultrasound (US) probe in both greyscale (GS) and power

N. Girolimetto $(\varangle) \cdot$ L. Costa · V. Bascherini . R. Peluso - V. Sabbatino - M. Tasso - S. Passavanti . R. Scarpa · F. Caso $(\bowtie)$

Department of Clinical Medicine and Surgery, Rheumatology Unit, University of Naples Federico II, via S. Pansini 5, 80131 Naples, Italy e-mail: nicolo.girolimetto@gmail.com

F. Caso

e-mail: francescocaso1@yahoo.it

N. Girolimetto · P. Macchioni · N. Possemato ·

G. Citriniti · G. Galletto · C. Salvarani

Department of Rheumatology, Azienda USL-IRCCS

Di Reggio Emilia, Reggio Emilia, Italy

I. Tinazzi · F. Martinis · A. Marchetta Unit of Rheumatology, IRCCS Sacro Cuore Don

Calabria Hospital, Negrar, Verona, Italy

C. Salvarani

Rheumatology Unit, University of Modena and

Reggio Emilia, Reggio Emilia, Italy
Doppler (PD). The presence of flexor tenosynovitis (FT), soft tissue oedema (STO), peritendon extensor inflammation and synovitis was assessed (including DACtylitis glObal Sonographic-DACTOS-score) before treatment, at 1-month (T1) and 3-months (T3) follow-up. LT was proposed to all patients. Patients refusing LT were treated with oral NSAIDs. Patients continued the same baseline csDMARDs and/or corticosteroid therapy during the whole followup period. US response was defined for DACTOS score $<3$ and US remission for DACTOS score $=0$.

Results: At T3 evaluation the ST group showed a significantly higher persistence (grade $>1$ ) of FT and STO $(p<0.001$ for all) and MCP synovitis $\quad(p=0.001)$. US remission was achieved only in the LT group (at T3 31\% vs. 0 , $p<0.001$ ). The percentage of patients with DACTOS $<3$ was significantly greater in the LT group compared with ST group, at both T1 (49\% vs. $5 \%, p<0.001)$ and $\mathrm{T} 3$ evaluation $(76 \%$ vs. $7 \%, p<0.001)$. In multiple conditional logistic regression analysis, the only factor associated with US remission was LT (T3 odds ratio = 41.21, $p<0.001$ ).

Conclusions: US confirmed the effectiveness of steroid injection for dactylitis by demonstrating that it involves the resolution of extra-articular inflammation, in particular FT and STO. 
Keywords: Dactylitis; Psoriatic arthritis; Treatment; Steroid injection; Flexor tenosynovitis; Digital flexor tendon sheath

\section{Key Summary Points}

Why carry out this study?

The study aimed to assess ultrasound effectiveness of steroid injection into the digital flexor tendon sheath for the treatment of psoriatic dactylitis compared to systemic treatment alone

The study evaluated modifications of clinical and ultrasound lesions induced by steroid injection into or in close proximity to the digital flexor tendon sheath of dactylitic digits in comparison with use of an NSAID treatment course

The study explored associations between specific ultrasound findings and clinical parameters of PsA activity

\section{What was learned from the study?}

A single steroid injection into or in close proximity to the digital flexor tendon sheath was sufficient to determine an important ultrasonographic and clinical response, maintained at 3 months

Ultrasound confirmed the effectiveness of steroid injection on dactylitis by demonstrating that it involves the resolution of extra-articular inflammation, in particular flexor tenosynovitis and soft tissue oedema

During the entire follow-up period, no injection-related side effects, such as subcutaneous fat tissue atrophy, skin hypopigmentation, tendon rupture or infection, were noted

\section{INTRODUCTION}

Dactylitis is a hallmark of psoriatic arthritis (PsA) and it is characterized by a diffuse and uniform swelling of a whole digit [1]. It has been included in the ClASsification for Psoriatic ARthritis (CASPAR) criteria [2,3] and it is a clinical marker of disease severity [4]. Dactylitis may be the first manifestation of PsA, occurring in up to $49 \%$ of PsA patients, and in some cases it can manifest as an isolated finding of the disease $[5,6]$. The most frequently used scores to evaluate dactylitis activity are the Leeds Dactylitis Index (LDI) and a simplified version, the LDI basic (LDI-b); both scores evaluate both finger circumference and tenderness $[7,8]$.

Several ultrasound (US) and magnetic resonance imaging (MRI) studies showed that dactylitis includes different inflammatory lesions such as flexor tenosynovitis (FT), soft tissue oedema (STO) and synovitis of metacarpophalangeal (MCP), proximal interphalangeal (PIP) and distal interphalangeal (DIP) joints [9-17].

Cross-sectional studies of our group have showed that specific US lesions (particularly FT and STO) are associated with high values of LDI$\mathrm{b}$ and local patient symptoms [18-21]. A recent longitudinal study highlighted that clinical responses in dactylitis are linked with sonographic improvement in extracapsular lesions (particularly FT and STO) [22]. At present, the only US measure for assessing the severity of dactylitis is the recently developed DACTylitis glObal Sonographic (DACTOS) score, which grades the characteristic US lesions of hand PsA dactylitis and it could be a useful tool for assessing the response to treatment [23].

The most common first-line therapies for dactylitis recommended by the Group for Research and Assessment of Psoriasis and PsA (GRAPPA) [24] and the European League Against Rheumatism (EULAR) [25] are non- 
steroidal anti-inflammatory drugs (NSAIDs) and local corticosteroid injections. Even though infiltrative therapy is commonly used in everyday clinical practice, this therapeutic strategy is largely empirical since no formal studies on local corticosteroid injections in PsA dactylitis have been published [26, 27]. A recent study of ours showed that steroid injections into the digital flexor tendon sheath could be an effective and safe first-line therapy for psoriatic dactylitis, but it included only clinical evaluation [28].

The aims of the present study were (1) to evaluate clinical and US effectiveness by steroid injection into or in close proximity to the digital flexor tendon sheath of dactylitic digits compared with the use of NSAID treatment course and (2) to explore associations between specific US findings and clinical parameters of disease activity.

\section{METHODS}

\section{Study Design and Patient Population}

This is a multicentre, longitudinal study conducted at three Italian rheumatology centres (University of Modena and Reggio Emilia, Italy; University Federico II, Naples, Italy; IRCCS Sacro Cuore Don Calabria Hospital, Negrar, Verona, Italy) enrolling consecutive PsA patients with symptomatic hand dactylitis. The present study is an extension of previously reported investigations [22, 28].

The study was approved by the local ethics committee (approval no. 824/18-RE), and it was conducted in conformity with the Declaration of Helsinki and its later amendments. Written informed consent for the anonymous use of data was obtained from all participants.

Consecutive PsA patients with symptomatic hands dactylitis were enrolled in the study. Exclusion criteria included: (1) axial involvement; (2) treatment with biological diseasemodifying antirheumatic drugs (bDMARDs) or targeted synthetic DMARDs; (3) Disease Activity Index for Psoriatic Arthritis (DAPSA) < 14; (4) previous dactylitis involving the finger under assessment; 5) previous steroid injection at the level of the affected finger.

The presence of active dactylitis was evaluated through physical examination by one rheumatologist from each centre (AM, CS, RS) and confirmed using the dactylometer and the related LDI-b $[7,8]$. The DAPSA was calculated for each patient at baseline [29].

When in an enrolled patient an additional finger became dactylitic during the enrolment period, it represented a new case of dactylitis and was included in the study. Any digit was considered as a distinct case and the newly symptomatic finger was evaluated through clinical assessment and US evaluation. A new case of dactylitis was included only if the previous one was completely solved.

\section{Treatment}

In accordance with international recommendations [24, 25], infiltrative therapy was offered to all patients as the first option. Patients who accepted the steroid injection were classified as local treatment (LT) group; those who refused local therapy underwent a 4 -week treatment with a full dose of NSAIDs and were classified in the systemic treatment (ST) group. In case of no clinical response after 1 month, they could change the type of NSAIDs. Patients of both groups continued the same baseline therapy with conventional synthetic DMARDs (csDMARDs) or oral corticosteroids for the entire duration of the follow-up.

In accordance with our clinical practice, all the patients of the LT group underwent steroidal injection after baseline examination by a rheumatologist for each centre (VB, FM, GC), blinded to the clinical data. A 25-gauge needle was used to inject $20 \mathrm{mg}$ methylprednisolone acetate (Depo-medrol, Pfizer, Italy) into the sheath of the flexor tendons, without US guidance.

\section{Ultrasound Assessment}

Sonographic evaluations of dactylitic fingers were executed by three operators (NG, PM, IT), with extensive experience in musculoskeletal 
US (MsK-US), using the same machine (MyLab70XVG-Esaote S.p.A., Genoa, Italy), employing a linear $6-18-\mathrm{MHz}$ transducer. The sonographers were blinded to treatment and were not aware of the clinical data.

US greyscale (GS) imaging was optimized for maximal image resolution. Power Doppler mode (PD) parameters were set as follows: $500-\mathrm{Hz}$ pulse repetition frequency, 3 wall filter, 4 persistence and $45-55 \%$ colour gain. Msk-US examinations were performed using a large quantity of gel to avoid probe contact with the skin.

Images of both the dactylitic digit and contralateral non-affected finger were acquired in the longitudinal and transverse planes from the dorsal and volar views according to currently accepted international guidelines [30]. Joint synovitis, flexor tenosynovitis (FT), subcutaneous oedema (STO) and peritendon extensor inflammation (PTI) were evaluated at metacarpophalangeal (MCP), proximal interphalangeal (PIP) and distal interphalangeal (DIP) joints, in both GS and PD mode. At baseline, T1 and T3, we examined every affected finger and the unaffected contralateral one.

The US assessment was performed at baseline (T0) and at the 1st and 3rd month post-procedure (T1 and T3, respectively). FT was assessed using the semi-quantitative (0-3) scoring system proposed by the Outcome Measures in Rheumatology (OMERACT) US group [31]. A semi-quantitative (0-3) score, described in a recent manuscript, was used for STO, comparing the dactylitic finger with the unaffected contralateral one $[23,32]$. PTI was evaluated as present/absent at MCP and PIP level, as reported in a previous study [23]. We used the EULAROMERACT GS and PD combined score (0-3) for evaluating joint synovitis at MCP, PIP and DIP level [33-35]. Moreover, we used the DACTOS score for every affected digit at T0, T1 and T3. It provided addition of the following US lesion scores: joint synovitis (0-3 for MCP, PIP and DIP), PTI (GS 0-1, PD 0-1 for MCP and PIP), FTO (GS 0-3, PD 0-3) and STO (GS 0-3, PD 0-3) [23].
US remission was defined as GS grade 0 and absence of power Doppler for all US sonographic lesions. A DACTOS value $<3$ identified the US response [36].

\section{Clinical Assessment}

Visual analogue scale (VAS) was provided to the patients as a tool to rate the functional impairment and local pain severity of the affected digit. The VAS-FI score, which is related to functional impairment, goes from 0 (no functional impairment) to 10 (total functional impairment). In addition, VAS pain (VAS-p), ranging from 0 (no pain) to 10 (worst possible pain), was used. These two parameters evaluated the finger affected by dactylitis. Clinical independent assessors (NP, FC, IT), blinded to treatment, evaluated outcomes at T0, T1 and T3. Clinical assessment comprised the physical examination of the finger affected by dactylitis, evaluation of the related LDI-b and recording of VAS-p and VAS-FI scores.

Meaningful treatment response (MTR) and clinical remission (CR) were based on definitions from previous studies [36]. All adverse events verified during the observation period were also recorded and evaluated.

\section{Statistical Analysis}

All qualitative variables were expressed in terms of percentages; quantitative variables were expressed as mean \pm SD or, in cases of strong deviation from normality, median and range. To compare non-continuous variables we used the chi-square test while continuous variables were compared using non-parametric or $t$-test, as appropriate.

The possible explanatory variables (demographic, laboratory, clinical and US) were entered as possible explanatory variables in a conditional logistic regression analysis with response at $\mathrm{T} 1$ and $\mathrm{T} 3$ examination as the dependent variable. The most significant independent variables were identified using a $p$-value 
$>0.10$ as the removal criterion using a backward selection procedure. Adequate intra- and inter-rater reliability were presumed based on significant agreement reported in previous studies $[18,19,21]$. Sensitivity to change of different US abnormalities was estimated using the standardized response mean (SRM) and its values were interpreted as trivial $(<0.2)$, small $(\geq 0.2$ and $<0.5)$, moderate $(\geq 0.5$ and $<0.8$ ) and moderate $(\geq 0.8)$ [37].

Significance level was set to $p<0.05$. All analyses were performed using SPSS V.23 (IBM Corp., NY, USA).

\section{RESULTS}

\section{Demographics and Clinical Characteristics}

A total of 88 dacylitic hand digits from 61 PsA patients (36 males and 25 females with mean age $47.2 \pm 15.1$ years) entered the study. No patient showed more than one dactylitic finger concomitantly. However, 15 patients presented more than one episode, verifying at the level of different fingers. Apart from hand dactylitis, all the enrolled patients showed PsA minimal disease activity (DAPSA $<14$ ) and continued the same baseline treatment (csDMARDs or oral corticosteroids or no treatment) throughout the follow-up period. Some patients did not take any baseline therapy with csDMARDs or oral corticosteroids because dactylitis was the only manifestation of the disease and, according to guidelines, they were treated only with injection or NSAIDs.

In Table 1, there are reported study patients and dactylitic fingers at T0. Thirty-one patients (45 dactylitic fingers) were treated with steroid injection and belonged to the LT group; 30 patients (43 dactylitic fingers) were managed with NSAIDs and were part of the ST group. Due to an acceptable response, no patient changed the type of NSAIDs at T1 and T3.

At baseline, a significant difference for VASFI (LT $7.8 \pm 1.6$ vs. ST $6.6 \pm 2.3, p=0.010$ ) between the two groups was reported; regarding sex, age, ESR, CRP, VAS-p and LDI-b no differences were identified. Furthermore, in the comparison between the two groups, the LT group had a higher percentage of patients without baseline therapy with csDMARDs or oral corticosteroids $(p=0.034)$.

\section{Ultrasound Findings}

Table 2 reported the prevalence of US abnormalities (and related grading) at baseline, T1 and T3 evaluations in LT and ST group. No baseline differences between the groups for individual US lesions were found. At T1 there was a statistically significant difference between the two groups for the following US parameters: GS FT $(p=0.002)$, PD FT $(p<0.001)$, GS STO $(p<0.001)$ and PD STO $(p<0.001)$. A similar statistically significant difference for the same US lesions was recorded at T3. The other US parameters did not change significantly except for MCP synovitis (combined score), which was lower in the ST group after 3 months $(p=0.018)$.

After 3 months we recorded the disappearance of some grade 3 US lesions (in particular PD FT, GS and PD STO) in the LT group, while the same US lesions were only reduced in the ST group.

At T3 evaluation the ST group showed a significantly higher persistence (grade $\geq 1$ ) of GS FT, PD FT, GS STO, PD STO $(p<0.001$ for all $)$ and MCP synovitis $(p=0.001)$ (see Table 3 and Fig. 1).

The SRMs between $\mathrm{T} 0$ and $\mathrm{T} 1$ and $\mathrm{T} 0$ and $\mathrm{T} 3$ evaluations were good for GS FT (0.87 and 1.17) and PD FT (0.97 and 1.08), moderate for GS STO (0.73 and 0.74) and PD STO (0.71 and 0.78) and trivial for the remaining lesions (0.02-0.22).

We observed US remission only in the LT group and, in particular, this was achieved in 3 and 14 cases at T1 and T3, respectively (at T1 7\% vs. $0, p=0.241$; at $\mathrm{T} 331 \%$ vs. $0, p<0.001$ ) (Fig. 2).

Regarding US response, the percentage of patients with DACTOS $<3$ was significantly greater in the LT group than in the ST group, at 
Table 1 Demographic and clinical characteristics at baseline of the two groups: local treatment group (LT) and systemic treatment group (ST)

\begin{tabular}{|c|c|c|c|c|}
\hline & Total & $\begin{array}{l}\text { LT } \\
31 \text { patients }(45 \mathrm{DF})\end{array}$ & $\begin{array}{l}\text { ST } \\
30 \text { patients } \\
(43 \mathrm{DF})\end{array}$ & $\overline{p \text { value }}$ \\
\hline \multicolumn{5}{|l|}{ Patients (61) } \\
\hline Female $n(\%)$ & $25(41 \%)$ & $14(31 \%)$ & $11(26 \%)$ & 0.401 \\
\hline Mean age, years $($ mean $\pm S D)$ & $47.2 \pm 15.1$ & $44.4 \pm 13.6$ & $46.7 \pm 15.3$ & 0.098 \\
\hline \multicolumn{5}{|l|}{ Dactylitic fingers (88) } \\
\hline Dactylitis duration, weeks (mean $\pm S D$ ) & $24.8 \pm 21.4$ & $25.5 \pm 29.9$ & $24.1 \pm 23$ & 0.765 \\
\hline PsA disease duration, months (mean $\pm \mathrm{SD}$ ) & $49.2 \pm 44.4$ & $41.8 \pm 35.7$ & $57 \pm 51.2$ & 0.111 \\
\hline $\mathrm{ESR}, \mathrm{mm} / \mathrm{h}($ mean $\pm \mathrm{SD})$ & $18 \pm 13.1$ & $11.8 \pm 10.2$ & $21.9 \pm 15.2$ & 0.056 \\
\hline CRP, mg/dl (median, IQR) & $0.3(0.2-0.9)$ & $0.3(0.2-0.8)$ & $0.4(0.2-0.9)$ & 0.628 \\
\hline TJC 68 joints $($ mean \pm SD) & $7.4 \pm 5.2$ & $7.6 \pm 5.7$ & $7.2 \pm 4.8$ & 0.737 \\
\hline SJC 66 joints (mean \pm SD) & $2.2 \pm 2.18$ & $3.2 \pm 2.4$ & $2.7 \pm 1.7$ & 0.887 \\
\hline DAPSA (median, IQR) & $2.2(1.1-5.1)$ & $2.3(1.2-7.2)$ & $2.1(0.8-4.5)$ & 0.455 \\
\hline MASES (mean \pm SD) & $0.8 \pm 1.12$ & $0.9 \pm 1$ & $0.4 \pm 0.9$ & 0.270 \\
\hline VAS-p (mean \pm SD) & $6.4 \pm 2.1$ & $6.4 \pm 1.9$ & $6.1 \pm 2.3$ & 0.062 \\
\hline VAS-FI $($ mean $\pm S D)$ & $7.2 \pm 2.2$ & $7.8 \pm 1.6$ & $6.6 \pm 2.3$ & 0.010 \\
\hline LDI-b $($ mean $\pm S D)$ & $13.7 \pm 8.4$ & $13.1 \pm 8.3$ & $14.4 \pm 10.4$ & 0.507 \\
\hline DACTOS (mean \pm SD) & $7.7 \pm 2.4$ & $7.5 \pm 2.1$ & $7.8 \pm 2.6$ & 0.414 \\
\hline No therapy $(n, \%)$ & $18(20 \%)$ & $14(31 \%)$ & $4(9 \%)$ & 0.034 \\
\hline csDMARDs $(n, \%)$ & $63(72 \%)$ & $29(65 \%)$ & $34(80 \%)$ & 0.084 \\
\hline Oral steroids $(n, \%)$ & $7(8 \%)$ & $2(4 \%)$ & $5(11 \%)$ & 0.421 \\
\hline
\end{tabular}

$p$ values $<0.05$ were considered statistically significant

CRP, C-reactive protein; csDMARDs, conventional synthetic disease-modifying antirheumatic drugs; DF, dactylitic fingers; ESR, erythrocyte sedimentation rate; LT, local treatment; MASES, Maastricht Ankylosing Spondylitis Enthesitis Score; PsA, psoriatic arthritis; SJC, swollen joint count; ST, systemic treatment; TJC, tender joint count

both T1 (50\% vs. 7\%, $p<0.001)$ and T3 evaluation (76\% vs. $7 \%, p<0.001)$ (Fig. 2 ). At T3, mean values of the VAS-p and VAS-FI were significantly higher in the group with DACTOS < 3 compared with the group with DACTOS $\geq 3$ $(1.49 \pm 1.72$ vs. $4.37 \pm 2.69, p=0.001$, for VAS$\mathrm{p}$ and $1.43 \pm 1.46$ vs. $4.98 \pm 2.81, p<0.001$, for VAS-FI).

Figure 3 shows an example of the US assessment at baseline and after 3 months in the LT group.

\section{Clinical Findings}

In both groups, there was a significant improvement in clinical parameters from $\mathrm{TO}$ to T1 and T3 (Table 4). This was not identified for T1 and T3 VAS-p in the ST group. Table 4 shows T0 values and T1 and T3 changes in VAS-p, VASFI and LDI-b in the LT and ST groups. The reduction of VAS-p, VAS-FI and LDI-b values was statistically significant in the LT group, at 
Table 2 Prevalence of individual ultrasound abnormalities at T1 and T3 examinations according to treatment (at T0, T1 and $\mathrm{T} 3$, respectively)

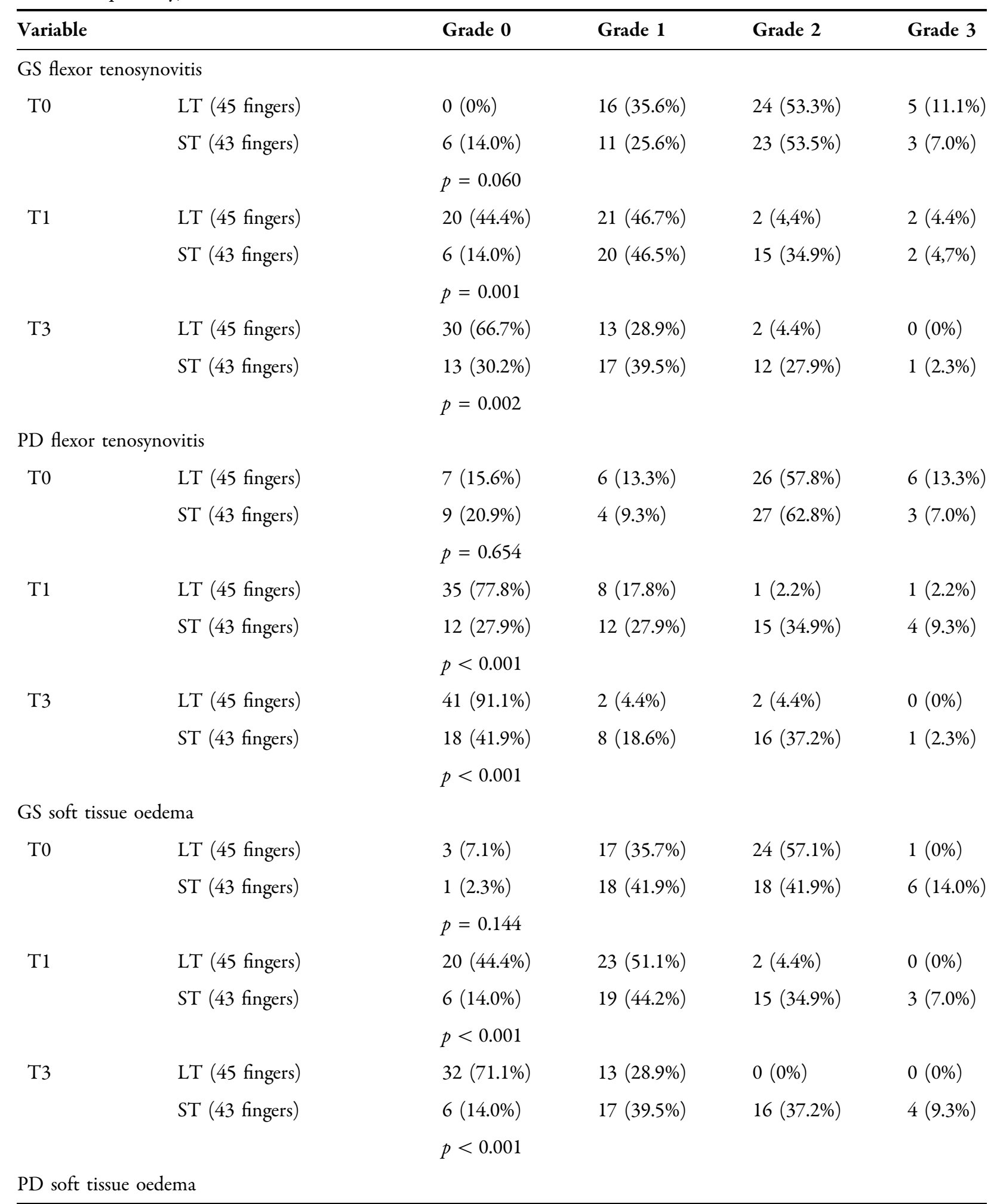


Table 2 continued

\begin{tabular}{|c|c|c|c|c|c|}
\hline Variable & & Grade 0 & Grade 1 & Grade 2 & Grade 3 \\
\hline \multirow[t]{3}{*}{ T0 } & LT (45 fingers) & $7(15.6 \%)$ & $11(24.4 \%)$ & $24(53.3 \%)$ & $3(6.7 \%)$ \\
\hline & ST (43 fingers) & $1(2.3 \%)$ & $16(37.2 \%)$ & $20(46.5 \%)$ & $6(14.0 \%)$ \\
\hline & & $p=0.080$ & & & \\
\hline \multirow[t]{3}{*}{$\mathrm{T} 1$} & LT (45 fingers) & $22(48.9 \%)$ & $17(37.8 \%)$ & $6(13.3 \%)$ & $0(0 \%)$ \\
\hline & ST (43 fingers) & $7(16.3 \%)$ & $14(32.6 \%)$ & $20(46.5 \%)$ & $2(4.7 \%)$ \\
\hline & & $p=0.001$ & & & \\
\hline \multirow[t]{3}{*}{$\mathrm{T} 3$} & LT (45 fingers) & $29(64.4 \%)$ & $12(26.7 \%)$ & $4(8.9 \%)$ & $0(0 \%)$ \\
\hline & ST (43 fingers) & $7(16.3 \%)$ & $16(37.2 \%)$ & $18(41.9 \%)$ & $2(4.7 \%)$ \\
\hline & & $p<0.001$ & & & \\
\hline \multicolumn{6}{|c|}{ MCP synovitis (combined score) } \\
\hline \multirow[t]{3}{*}{ T0 } & LT (45 fingers) & $42(93.3 \%)$ & $1(2.2 \%)$ & $2(4.4 \%)$ & $0(0 \%)$ \\
\hline & ST (43 fingers) & $35(81.4 \%)$ & $3(7.0 \%)$ & $2(4.7 \%)$ & $3(7.0 \%)$ \\
\hline & & $p=0.204$ & & & \\
\hline \multirow[t]{3}{*}{$\mathrm{T} 1$} & LT (45 fingers) & $42(93.3 \%)$ & $3(6.7 \%)$ & $0(0 \%)$ & $0(0 \%)$ \\
\hline & ST (43 fingers) & $37(86.0 \%)$ & $1(2.3 \%)$ & $2(4.7 \%)$ & $3(7.0 \%)$ \\
\hline & & $p=0.099$ & & & \\
\hline \multirow[t]{3}{*}{ T3 } & LT (45 fingers) & $45(100 \%)$ & $0(0 \%)$ & $0(0 \%)$ & $0(0 \%)$ \\
\hline & ST (43 fingers) & $34(79.1 \%)$ & $5(11.6 \%)$ & $2(4.7 \%)$ & $2(4.7 \%)$ \\
\hline & & $p=0.015$ & & & \\
\hline \multicolumn{6}{|c|}{ PIP synovitis (combined score) } \\
\hline \multirow[t]{3}{*}{ T0 } & LT (45 fingers) & $35(77.8 \%)$ & $1(2.2 \%)$ & $3(6.7 \%)$ & $6(13.3 \%)$ \\
\hline & ST (43 fingers) & $30(69.8 \%)$ & $2(4.7 \%)$ & $6(14.0 \%)$ & $5(11.6 \%)$ \\
\hline & & $p=0.623$ & & & \\
\hline \multirow[t]{3}{*}{$\mathrm{T} 1$} & LT (45 fingers) & $34(75.6 \%)$ & $3(6.7 \%)$ & $2(4.4 \%)$ & $6(13.3 \%)$ \\
\hline & ST (43 fingers) & $30(69.8 \%)$ & $2(4.7 \%)$ & $5(11.6 \%)$ & $6(14.0 \%)$ \\
\hline & & $p=0.639$ & & & \\
\hline \multirow[t]{3}{*}{$\mathrm{T} 3$} & LT (45 fingers) & $35(77.8 \%)$ & $0(0 \%)$ & $5(11.1 \%)$ & $5(11.1 \%)$ \\
\hline & ST (43 fingers) & $30(69.8 \%)$ & $2(4.7 \%)$ & $7(16.3 \%)$ & $4(9.3 \%)$ \\
\hline & & $p=0.426$ & & & \\
\hline
\end{tabular}

DIP synovitis (combined score)

\begin{tabular}{llllll} 
T0 & LT (45 fingers) & $42(93.3 \%)$ & $0(0 \%)$ & $3(6.7 \%)$ & $0(0 \%)$ \\
& ST (43 fingers) & $39(90.7 \%)$ & $1(2,3 \%)$ & $3(7.0 \%)$ & $0(0 \%)$ \\
\hline
\end{tabular}


Table 2 continued

\begin{tabular}{|c|c|c|c|c|c|}
\hline Variable & & Grade 0 & Grade 1 & Grade 2 & Grade 3 \\
\hline & & $p=0.587$ & & & \\
\hline \multirow[t]{3}{*}{$\mathrm{T} 1$} & LT (45 fingers) & $42(93.3 \%)$ & $0(0 \%)$ & $3(6.7 \%)$ & $0(0 \%)$ \\
\hline & ST (43 fingers) & $39(90.7 \%)$ & $0(0 \%)$ & $4(9.3 \%)$ & $0(0 \%)$ \\
\hline & & $p=648$ & & & \\
\hline \multirow[t]{3}{*}{ T3 } & LT (45 fingers) & $44(97.8 \%)$ & $0(0 \%)$ & $1(2.2 \%)$ & $0(0 \%)$ \\
\hline & ST (43 fingers) & $39(90.7 \%)$ & $0(0 \%)$ & $4(9.3 \%)$ & $0(0 \%)$ \\
\hline & & $p=0.152$ & & & \\
\hline
\end{tabular}

The values of the prevalence of peritendon extensor inflammation are not reported because of the few cases recorded ( $p$ not significant)

DIP, distal interphalangeal; GS, greyscale; MCP, metacarpophalangeal; MTR, meaningful treatment response; PD, power Doppler; PIP, proximal interphalangeal; T0, baseline; T1, 1 month; T3, 3 months

both T1 $(p<0.001, p<0.001$ and $p=0.007$, respectively) and T3 evaluation ( $p<0.001$ for all). The percentage of patients achieving MTR was significantly greater in the LT group than in the ST group, at both $\mathrm{T} 1 \quad(73 \%$ vs. $14 \%$, $p<0.001)$ and $\mathrm{T} 3$ evaluation $(76 \%$ vs. $14 \%$, $p<0.001)$. Clinical remission was only observed in the LT group (3 cases at T1, $p=0.322$, and 10 cases at $\mathrm{T} 3, p<0.001)$. In both groups, we did not observe systemic or local adverse events during the entire follow-up.

\section{Correlation Between Ultrasound and Clinical Parameters}

Using multiple logistic regression analysis, we found that treatment with local injection represented the only variable associated with US remission (odds ratio T1 $13.33 \quad(95 \%$ CI $3.52-49.60, p<0.001)$, odds ratio T3 41.21 (95\% CI 10.62-159.92, $p<0.001)$. All the other variables [age, sex, body mass index (BMI), dactylitis duration, PsA disease duration, ESR, CRP, TJC, SJC, therapy with csDMARDs or oral corticosteroids] had no influence on the outcome.

In multiple conditional logistic regression analysis, the only factors associated with the DACTOS score $<3$ at T3 were treatment with local injection [odds ratio 70.77 (95\% CI 14.826-337.88, $p<0.001)]$ and duration of dactylitis [odds ratio 0.95 (95\% CI 0.92-0.99, $p=0.002$ )]. All the other variables (age, sex, BMI, dactylitis duration, PsA disease duration, ESR, CRP, TJC, SJC, therapy with csDMARDs or oral corticosteroids) had no influence on the outcome.

When US features were entered in a multiple conditional logistic regression analysis, only the resolution of PD FT [15.66 OR (3.52-69.67) $p<0.001]$ and PD STO [6.23 OR (1.27-30.60) $p=0.024]$ was correlated with MTR at T1 $(\mathrm{R} 2=0.365)$, whereas the resolution of PD FT [OR $27.77(4.68-164.62) p=0.041]$ and of GS STO [OR $7.29(1.08-48.98) p=0.041]$ was associated with MTR at T3 $(\mathrm{R} 2=0.437)$. Neither GS nor PD changes of US synovitis or PTI were correlated with clinical responses.

\section{DISCUSSION}

To the best of our knowledge this study is the first to address the US response in PsA dactylitis treated with steroid injection. Our findings demonstrate that inflammatory activity around and within the tendon sheath is reduced by infiltrative therapy. Furthermore, we found that patients with FT and STO responded 
Table 3 Prevalence of ultrasound abnormalities of the two groups at 3 months

\begin{tabular}{|c|c|c|c|}
\hline Variable & $\begin{array}{l}\text { LT } \\
45 \\
\text { fingers }\end{array}$ & $\begin{array}{l}\text { ST } \\
43 \\
\text { fingers }\end{array}$ & $p$ \\
\hline $\begin{array}{l}\text { GS flexor } \\
\text { tenosynovitis } \\
\text { grade } \geq 1\end{array}$ & $\begin{array}{l}15 \\
(33.3 \%)\end{array}$ & $\begin{array}{l}30 \\
\quad(69.8 \%)\end{array}$ & $<0.001$ \\
\hline $\begin{array}{l}\text { PD flexor } \\
\text { tenosynovitis } \\
\text { grade } \geq 1\end{array}$ & $4(8.9 \%)$ & $\begin{array}{l}26 \\
(60.5 \%)\end{array}$ & $<0.001$ \\
\hline $\begin{array}{l}\text { GS soft tissue oedema } \\
\text { grade } \geq 1\end{array}$ & $\begin{array}{l}13 \\
(28.9 \%)\end{array}$ & $\begin{array}{l}36 \\
(83.7 \%)\end{array}$ & $<0.001$ \\
\hline $\begin{array}{l}\text { PD soft tissue oedema } \\
\text { grade } \geq 1\end{array}$ & $\begin{array}{l}16 \\
(35.6 \%)\end{array}$ & $\begin{array}{l}36 \\
\quad(83.7 \%)\end{array}$ & $<0.001$ \\
\hline $\begin{array}{l}\text { MCP synovitis } \\
\text { (combined score) } \\
\text { grade } \geq 1\end{array}$ & 0 & $9(20.9 \%)$ & 0.001 \\
\hline $\begin{array}{l}\text { PIP synovitis } \\
\text { (combined score) } \\
\text { grade } \geq 1\end{array}$ & $\begin{array}{l}10 \\
(22.2 \%)\end{array}$ & $\begin{array}{l}36 \\
\quad(83.7 \%)\end{array}$ & 0.470 \\
\hline $\begin{array}{l}\text { DIP synovitis } \\
\text { (combined score) } \\
\text { grade } \geq 1\end{array}$ & $1(2.2 \%)$ & $4(9.3 \%)$ & 0.198 \\
\hline
\end{tabular}

The values of the prevalence of peritendon extensor inflammation are not reported because of the few cases recorded ( $p$ not significant)

DIP, distal interphalangeal; GS, greyscale; LT, local treatment group; MCP, metacarpophalangeal; PD, power Doppler; PIP, proximal interphalangeal; ST, systemic treatment group

significantly better by US assessment when treated with steroid injection compared to systemic treatment with NSAIDs, at both 1 and 3 months.

From the results of this study, we can derive very useful information for the clinician. First, a single steroid injection into or in close proximity to the digital flexor tendon sheath was sufficient to determine an important US and clinical response. This response was maintained at 3 months and during the entire follow-up period we did not observe any injection-related side effects, such as subcutaneous fat tissue atrophy, skin hypopigmentation, tendon rupture or infection. Consistent with the results of our previous study [28], we observed a stronger and faster effectiveness on VAS-p, VAS-FI and LDI-b in patients undergoing local steroid injection (in some cases combined with csDMARDs or oral corticosteroids) compared with patients on therapy with oral NSAIDs plus csDMARDs or oral corticosteroids.

In line with the GRAPPA recommendations [24], our study shows that local treatment, as well NSAIDs, could be considered a valid therapeutic approach during the acute phase of dactylitis. However, there are still very few data on efficacy and effectiveness of local steroid injection for PsA dactylitis. Further studies on this topic are advocated.

Furthermore, data from our study show that local steroid injection in or near the flexor tendon sheath determines the resolution of all the US lesions characteristic of hand dactylitis.

Previous studies demonstrated that the sausage finger appearance is supported by the presence of FT and STO [18, 19, 21]. In our cohort, cases treated with infiltration showed faster resolution of FT and STO than those treated with NSAIDs. Some studies demonstrated the efficacy of US-guided peritendinous steroid injections in the management of flexor tenosynovitis in patients with chronic inflammatory arthritis [39-41]. A superiority of USguided tendon sheath injections over convectional blind injection in patients with flexor tenosynovitis has been reported, obtaining a better response measured with clinical and US outcomes [40]. However, a conventional blind injection of corticosteroids near or into the tendon sheath may reduce clinical pain and allow improvement in functional capacity [40]. It is important to highlight that our protocol did not include US-guided infiltration. A nonUS guided approach is more common in everyday clinical practice. In fact, in many centres the rheumatologist may not have an US machine or may not be able to use it. In the light of our results, injection without US guidance into or in close proximity to the tendon sheath should be considered an optimal 


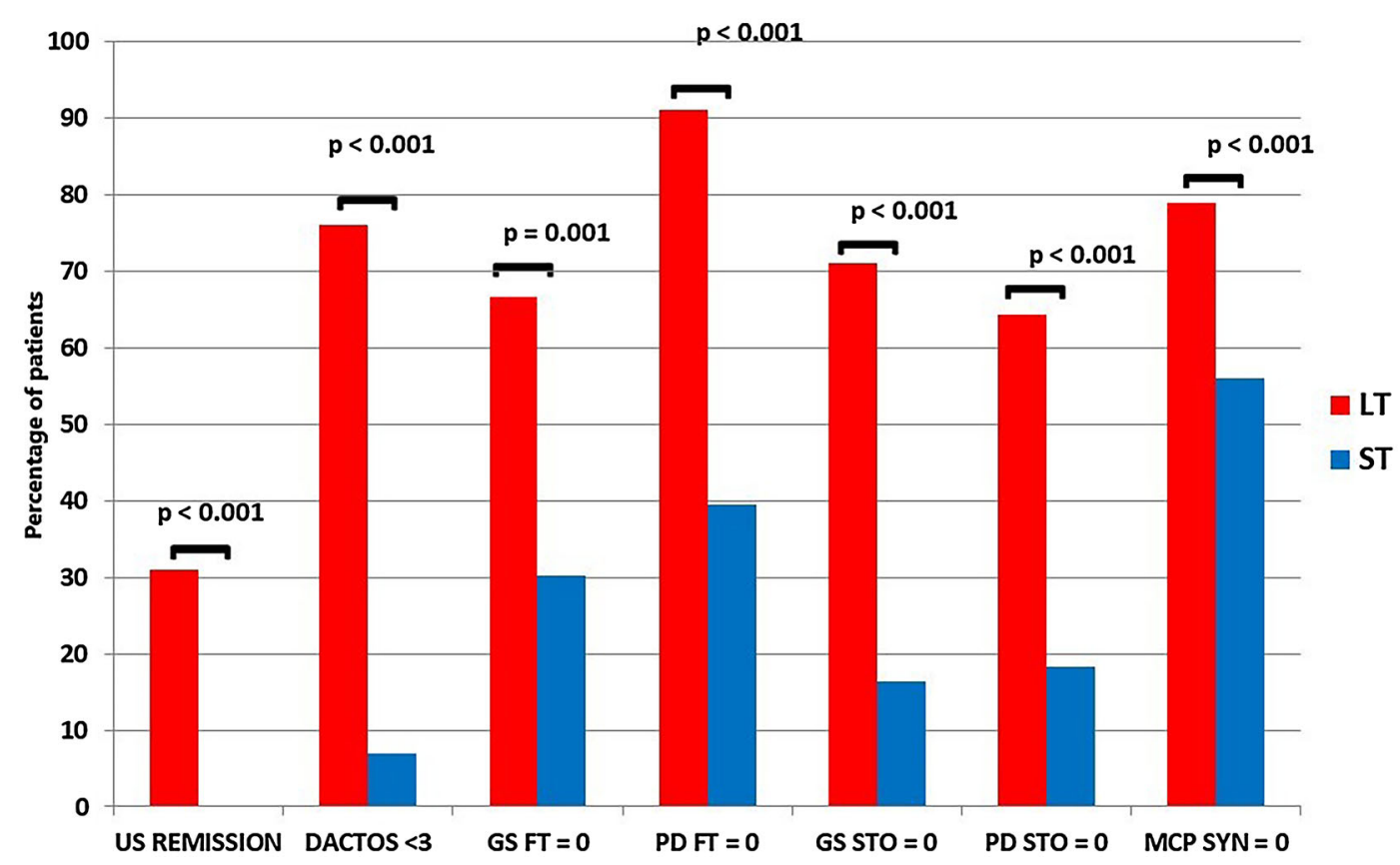

Fig. 1 Comparison of US features at 3-month evaluation (T3) of the two groups: local treatment (LT) group and systemic treatment (ST) group. DACTOS, DACTylitis
glObal Sonographic; FT, flexor tenosynovitis; GS, greyscale; MCP, metacarpophalangeal; PD, power Doppler; STO, soft tissue oedema; SYN, synovitis

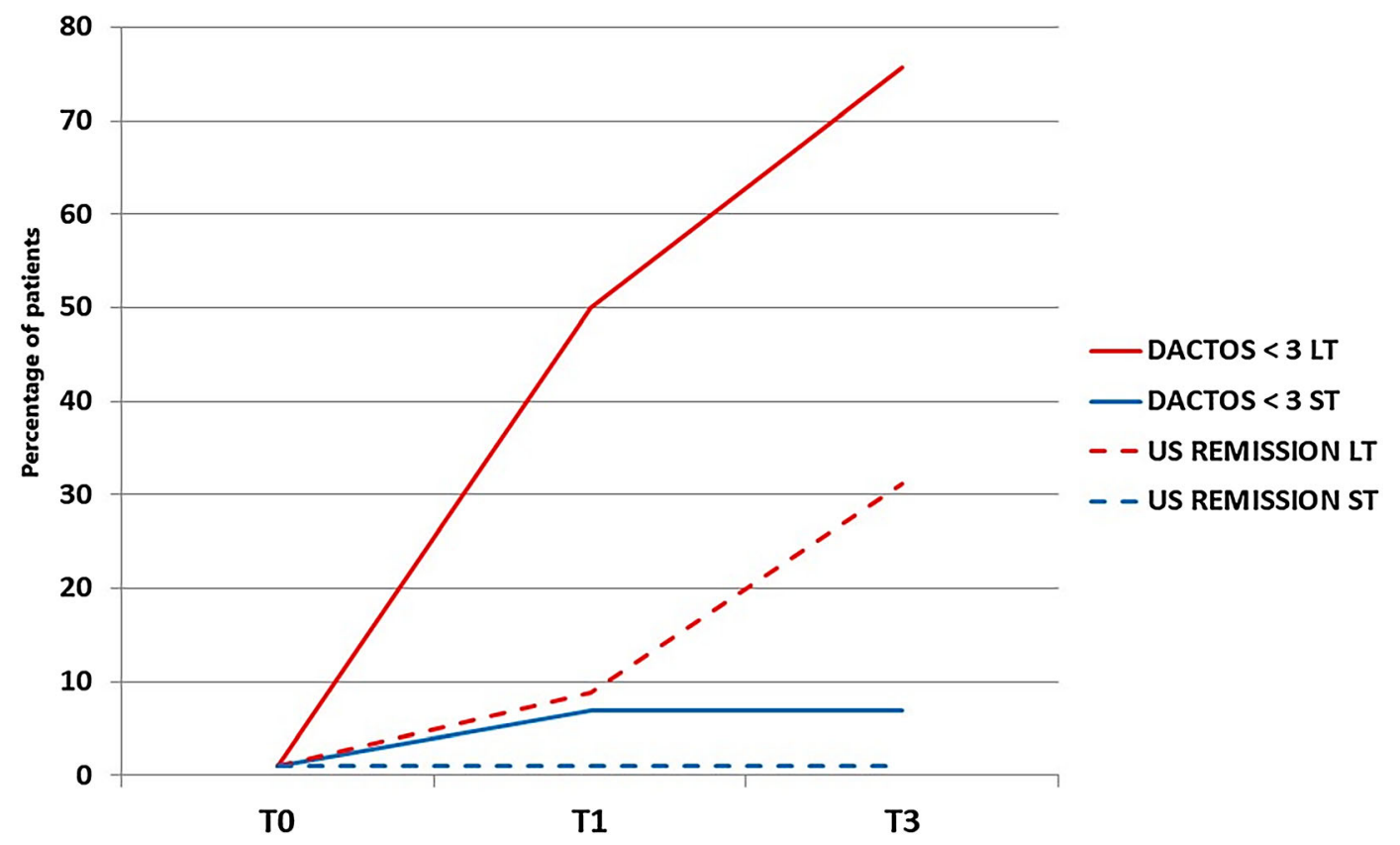

Fig. 2 Evolution of the US scores during follow-up. The percentage of patients with DACTOS $<3$ and US remission was significantly greater in the local treatment

(LT) group compared with the systemic treatment (ST) group, at both $\mathrm{T} 1$ and $\mathrm{T} 3$ evaluation 

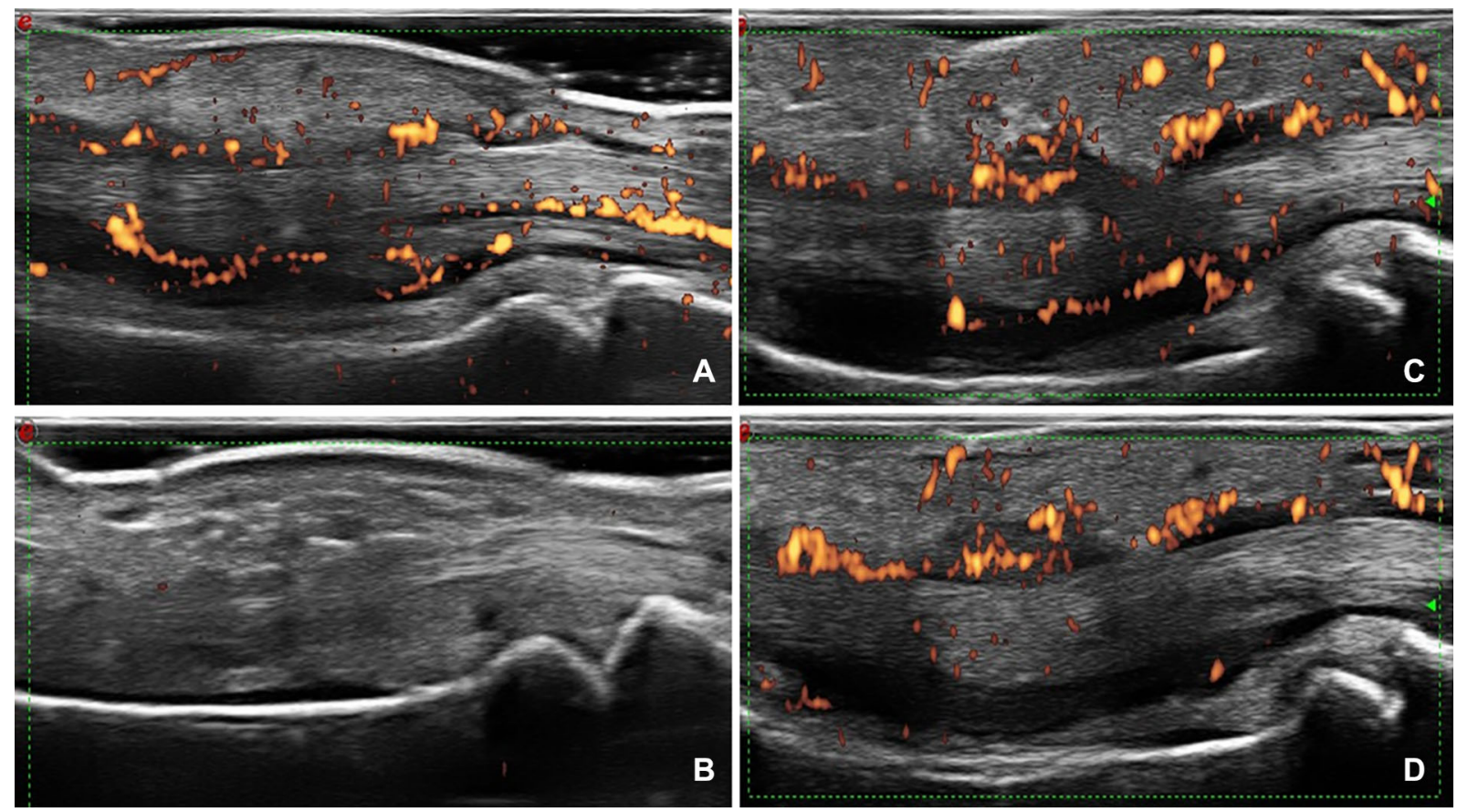

Fig. 3 Volar scan of a dactylitic digit after local (A, B) and systemic $(\mathbf{C}, \mathbf{D})$ treatment. A Flexor tenosynovitis and soft tissue oedema at baseline. B One month after the steroid injection we can appreciate the complete resolution of the

approach for FT in dactylitic fingers, ensuring excellent results in terms of US and clinical response.

Additionally, results from our study show that cases treated with local injection had a more rapid improvement in US lesions (in both GS and PD scale) than those treated with NSAIDs. US examination shows that steroid injection can rapidly reduce local inflammation, which is maintained during the whole follow-up period. All the cases in the LT group who were in US remission at T1 maintained this condition at T3 examination. In the ST group, no cases of US remission were observed during the 3-month follow-up.

This study also demonstrated that US is a key tool in monitoring response to treatment in hand dactylitis; therefore, our results are in line with the large amount of data supporting the role of US as a procedure for helping clinicians in monitoring articular and periarticular inflammation after infiltrative therapy [39-43].

inflammatory involvement at the flexor tendon and soft tissue level. C Longitudinal view at baseline. D After 1 month of NSAID therapy, ultrasound shows persistence of flexor tenosynovitis and soft tissue edema

Moreover, the resolution of FT and sto was correlated with clinical remission, confirming that these two lesions are the major factors responsible for local pain and functional limitation [18, 20, 22-36].

We have observed that infiltrative therapy does not seem to modify the presence of joint synovitis; if present at baseline it may remain even after 3 months, regardless of clinical response. Thus, in line with previous studies, US evidence of synovitis seems to have no correlation with local pain $[18,19,21]$.

Moreover, results from our study highlight that US findings are consistent with clinical aspects: at T3 the clinical parameters (VAS-p and VAS-FI) were significantly lower in patients who have an US response (DACTOS $<3$ ). We chose this cut-off value to identify an US response because a recent study showed that the optimal cut-off value of DACTOS to distinguish between a "healthy" and "pathological" finger was a score of 3 [36]. The outcome US measures 


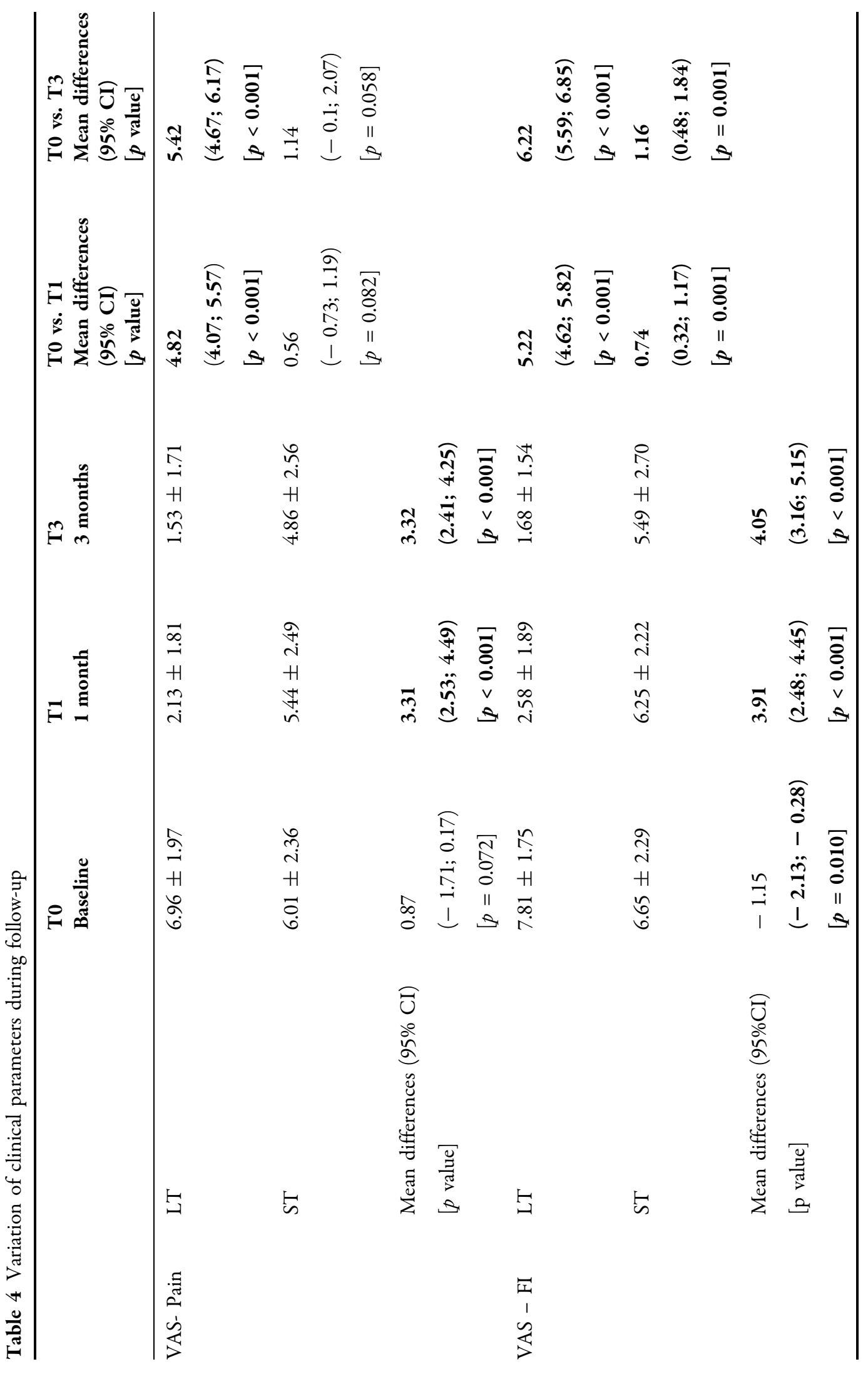




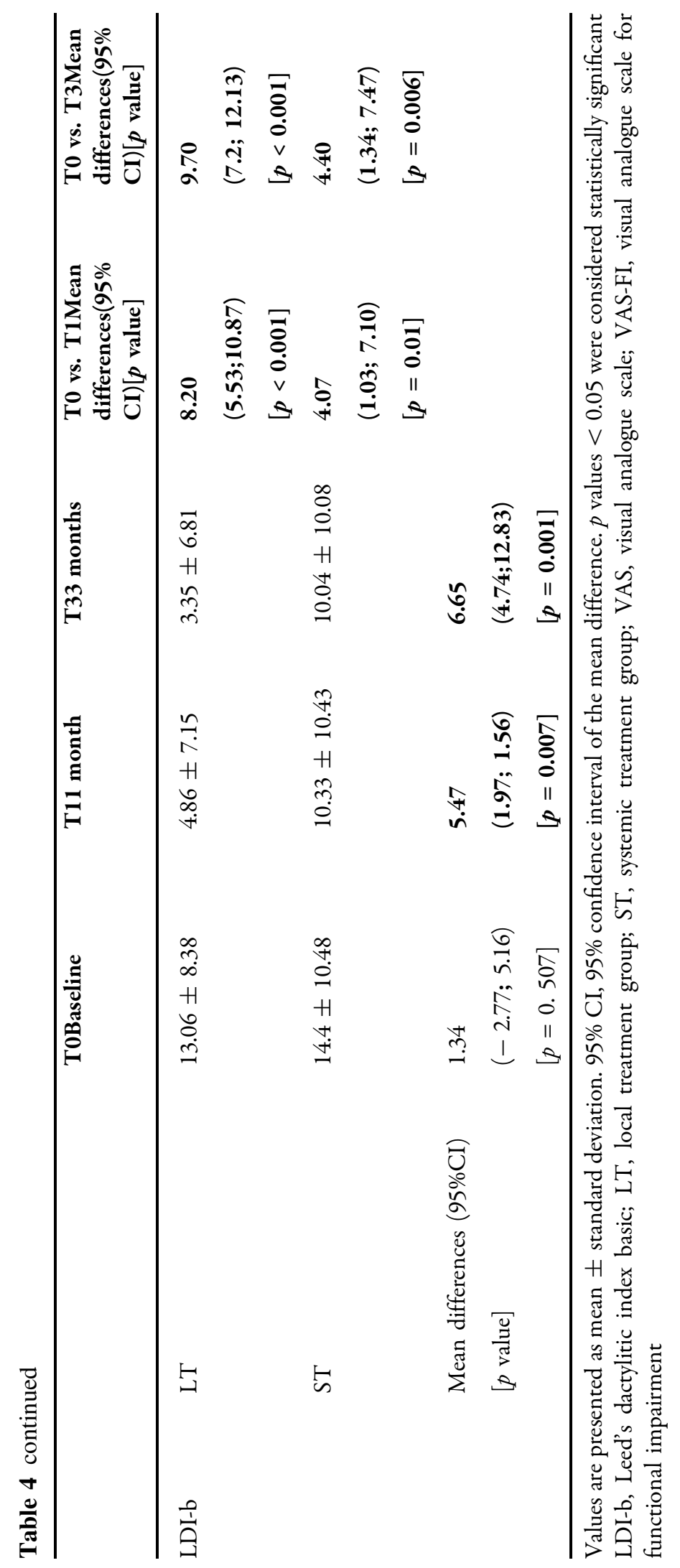


that we used (US remission and US response as DACTOS $<3$ ) [36] have shown a good correlation with clinical improvement suggesting that they may be appropriate for assessing the effectiveness of treatment.

Finally, our study shows that patients affected by dactylitis can benefit from early treatment with steroid injection in terms of US and clinical response. In particular, our findings show that reducing the temporal range between dactylitis diagnosis and steroid injection can be effective in improving patient outcomes, suggesting also for this case "the sooner, the better". In fact, the results of the logistic regression show that the therapeutic effect of injection is better if performed in the early stages of dactylitis.

This study had several limitations, the major one being the lack of randomization because patients arbitrarily chose LT; this fact could constitute a limitation of the study but on the other hand it reflects the common clinical practice. No placebo arm treatment was considered. However, we have partly overcome this bias by employing an independent US assessor blind to treatment. Another limitation of our study was represented by the short length of follow-up (3 months). It is necessary to extend the evaluation period to assess the efficacy of the steroid injection in the long term. On the other hand, in a follow-up period of $>3$ months it is common to make changes to the oral therapy and this aspect could be a further confounding factor. Furthermore, it would be necessary to validate our current results in a larger number of cases.

\section{CONCLUSION}

To the best of our knowledge, this is the first study that provides evidence of the value of US in the detection of changes induced by local steroid injection in the flexor tendon sheaths of patients with acute dactylitis. Such changes can be clearly seen even after a short-term follow-up and maintained for at least 3 months with good correlation with the clinical evolution of the dactylitis. US examination of dactylitic fingers may be considered a useful adjunctive tool for assessing articular and extra-articular changes after steroid injection in the flexor tendon sheath of patients with acute dactylitis.

\section{ACKNOWLEDGEMENTS}

We thank the participants of the study.

Funding. No funding or sponsorship was received for this study or publication of this article.

Authorship. All named authors meet the International Committee of Medical Journal Editors (ICMJE) criteria for authorship for this article, take responsibility for the integrity of the work as a whole and have given their approval for this version to be published.

Authorship Contributions. Nicolò Girolimetto, Pierluigi Macchioni, Ilaria Tinazzi, Niccolò Possemato, Luisa Costa, Raffaele Scarpa, Carlo Salvarani, Francesco Caso: conception and design of the study, acquisition of data, analysis and interpretation of data, drafting the article, revising it critically for important intellectual content and final approval of the version to be submitted. Vittoria Bascherini, Rosario Peluso, Giorgia Citriniti, Giulia Galletto, Federica Martinis, Antonio Marchetta, Vincenzo Sabbatino, Marco Tasso, Saverio Passavanti: acquisition of data, analysis and interpretation of data, approval of the version to be submitted.

Disclosures. The authors Nicolò Girolimetto, Pierluigi Macchioni, Ilaria Tinazzi, Niccolò Possemato, Luisa Costa, Vittoria Bascherini, Rosario Peluso, Giorgia Citriniti, Giulia Galletto, Federica Martinis, Antonio Marchetta, Vincenzo Sabbatino, Marco Tasso, Saverio Passavanti, Carlo Salvarani, Raffaele Scarpa, Francesco Caso have nothing to disclose in relation to the study.

Compliance with Ethics Guidelines. This study was conducted in accordance with the Declaration of Helsinki. This study was conducted with approval from the by the RE ethical committees (EC reference number: 824/18RE). 
Written informed consent was obtained from all participants.

Data Availability. The datasets generated during and/or analyzed during the current study are available from the corresponding authors on reasonable request.

Open Access. This article is licensed under a Creative Commons Attribution-NonCommercial 4.0 International License, which permits any non-commercial use, sharing, adaptation, distribution and reproduction in any medium or format, as long as you give appropriate credit to the original author(s) and the source, provide a link to the Creative Commons licence, and indicate if changes were made. The images or other third party material in this article are included in the article's Creative Commons licence, unless indicated otherwise in a credit line to the material. If material is not included in the article's Creative Commons licence and your intended use is not permitted by statutory regulation or exceeds the permitted use, you will need to obtain permission directly from the copyright holder. To view a copy of this licence, visit http://creativecommons.org/licenses/bync/4.0/.

\section{REFERENCES}

1. Gladman DD, Ziouzina $\mathrm{O}$, Thavaneswaran A, Chandran V. Dactylitis in psoriatic arthritis: prevalence and response to therapy in the biologic era. J Rheumatol. 2013;40:1357-9.

2. Taylor W, Gladman D, Helliwell P, Marchesoni A, Mease P, Mielants H. Classification criteria for psoriatic arthritis: development of new criteria from a large international study. Arthritis Rheum. 2006;54: 2665-73.

3. Tillett W, Costa L, Jadon D, Wallis D, Cavill C, McHugh J, et al. The ClASsification for Psoriatic ARthritis (CASPAR) criteria-a retrospective feasibility, sensitivity, and specificity study. J Rheumatol. 2012;39:154-6.

4. Brockbank JE, Stein M, Schentag CT, Gladman DD. Dactylitis in psoriatic arthritis: a marker for disease severity? Ann Rheum Dis. 2005;64:188-90.
5. Kaeley GS, Eder L, Aydin SZ, Gutierrez M, Bakewell C. Dactylitis: a hallmark of psoriatic arthritis. Semin Arthritis Rheum. 2018;48:263-73.

6. Caso F, Costa L, Atteno M, Del Puente A, Cantarini L, Lubrano E, Scarpa R. Simple clinical indicators for early psoriatic arthritis detection. Springerplus. 2014;22(3):759.

7. Helliwell PS, Firth J, Ibrahim GH, Melsom RD, Shah I, Turner DE. Development of an assessment tool for dactylitis in patients with psoriatic arthritis. J Rheumatol. 2005;32:1745-50.

8. Healy PJ, Helliwell PS. Measuring dactylitis in clinical trials: which is the best instrument to use? J Rheumatol. 2007;34:1302-6.

9. Olivieri I, Barozzi L, Pierro A, De Matteis M, Padula A, Pavlica P. Toe dactylitis in patients with spondyloarthropathy: assessment by magnetic resonance imaging. J Rheum. 1997;24:926-30.

10. Olivieri I, Scarano E, Padula A, D'Angelo S, Salvarani C, Cantini F, et al. Fast spin echo-T2weighted sequences with fat saturation in toe dactylitis of spondyloarthritis. Clin Rheumatol. 2008;27:1141-5.

11. Healy PJ, Groves C, Chandramohan M, Helliwell PS. MRI changes in psoriatic dactylitis-extent of pathology, relationship to tenderness and correlation with clinical indices. Rheumatol (Oxf). 2008;47:92-5.

12. Tan AL, Fukuba E, Halliday NA, Tanner SF, Emery P, McGonagle D. High-resolution MRI assessment of dactylitis in psoriatic arthritis shows flexor tendon pulley and sheath-related enthesitis. Ann Rheum Dis. 2015;74:185-9.

13. Olivieri I, Barozzi L, Favaro L, Pierro A, de Matteis M, Borghi C, et al. Dactylitis in patients with seronegative spondylarthropathy. Assessment by ultrasonography and magnetic resonance imaging. Arthritis Rheum. 1996;39:1524-8.

14. Fournié B, Margarit-Coll N, de Ribes TLC, Zabraniecki L, Jouan A, Vincent $\mathrm{V}$, et al. Extrasynovial ultrasound abnormalities in the psoriatic finger. Prospective comparative power-doppler study versus rheumatoid arthritis. Joint Bone Spine. 2006;73: 527-31.

15. Wakefield RJ, Emery P, Veale D. Ultrasonography and psoriatic arthritis. J Rheumatol. 2000;27: 1564-5.

16. Kane D, Greaney T, Bresnihan B, Gibney R, FitzGerald O. Ultrasonography in the diagnosis and management of psoriatic dactylitis. J Rheumatol. 1999;26:1746-51. 
17. Soscia E, Sirignano C, Catalano O, Atteno M, Costa L, Caso F, Peluso R, Bruner V, Aquino MM, Del Puente A, Salvatore M, Scarpa R. New developments in magnetic resonance imaging of the nail unit. J Rheumatol Suppl. 2012;89:49-53.

18. Girolimetto N, Macchioni P, Tinazzi I, Costa L, Peluso R, Tasso M, et al. Association between Leeds Dactylitis Index and ultrasonographic features: a multicentre study on psoriatic hand dactylitis. Clin Exp Rheumatol. 2020;38:1112-7.

19. Girolimetto N, Macchioni P, Tinazzi I, Costa L, Peluso R, Tasso M, et al. Predominant ultrasonographic extracapsular changes in symptomatic psoriatic dactylitis: results from a multicenter crosssectional study comparing symptomatic and asymptomatic hand dactylitis. Clin Rheumatol. 2020;39:1157-65.

20. Girolimetto N, Costa L, Mancarella L, Addimanda O, Bottiglieri P, Santelli F, et al. Symptomatic psoriatic dactylitis is associated with ultrasound determined extra-synovial inflammatory features and shorter disease duration. Clin Rheumatol. 2019;38: 903-11.

21. Girolimetto N, Macchioni P, Tinazzi I, Costa L, McGonagle D, Peluso R, et al. Ultrasonographic evidence of predominance of acute extracapsular and chronic intrasynovial patterns in 100 cases of psoriatic hand dactylitis. J Rheumatol. 2020;47: 227-33.

22. Girolimetto N, Macchioni P, Possemato N, Tinazzi I, Bascherini V, Citriniti G, et al. Musculoskeletal ultrasound in monitoring clinical response to treatment in acute symptomatic psoriatic dactylitis: results from a multicentre prospective observational study. J Clin Med. 2020;2020:9.

23. Zabotti A, Sakellariou G, Tinazzi I, Idolazzi L, Batticciotto A, Canzoni $\mathrm{M}$, et al. Novel and reliable DACTylitis glObal Sonographic (DACTOS) score in psoriatic arthritis. Ann Rheum Dis. 2020;79: 1037-43.

24. Coates LC, Kavanaugh A, Mease PJ, Soriano ER, Laura Acosta-Felquer M, Armstrong AW, et al. Group for research and assessment of psoriasis and psoriatic arthritis 2015 treatment recommendations for psoriatic arthritis. Arthritis Rheumatol. 2016;68:1060-71.

25. Gossec L, Smolen JS, Ramiro S, de Wit M, Cutolo M, Dougados M, et al. European League Against Rheumatism (EULAR) recommendations for the management of psoriatic arthritis with pharmacological therapies: 2015 update. Ann Rheum Dis. 2016;75:499-510.
26. Rose S, Toloza S, Bautista-Molano W, Helliwell PS. Comprehensive treatment of dactylitis in psoriatic arthritis. J Rheumatol. 2014;41:2295-300.

27. McGonagle D, Tan AL, Watad A, Helliwell P. Pathophysiology, assessment and treatment of psoriatic dactylitis. Nat Rev Rheumatol. 2019;15: $113-22$.

28. Girolimetto N, Macchioni P, Citriniti G, Tinazzi I, Bascherini V, Martinis F, et al. Effectiveness of steroid injection for hand psoriatic dactylitis: results from a multicentre prospective observational study. Clin Rheumatol. 2020;39:3383-92.

29. Schoels MM, Aletaha D, Alasti F, Smolen JS. Disease activity in psoriatic arthritis (PsA): defining remission and treatment success using the DAPSA score. Ann Rheum Dis. 2016;75:811-8.

30. Möller I, Janta I, Backhaus M, Ohrndorf S, Bong DA, Martinoli C, et al. The 2017 EULAR standardised procedures for ultrasound imaging in rheumatology. Ann Rheum Dis. 2017;76:1974-9.

31. Naredo E, D'Agostino MA, Wakefield RJ, Möller I, Balint PV, Filippucci E, et al. Reliability of a consensus-based ultrasound score for tenosynovitis in rheumatoid arthritis. Ann Rheum Dis. 2013;72: 1328-34.

32. Tinazzi I, Idolazzi L, Zabotti A, Arancio L, Batticiotto A, Caimmi C, et al. Ultrasonographic detection, definition and quantification of soft tissue oedema in psoriatic dactylitis. Med Ultrason. 2019;21:414-21.

33. Bruyn GA, Iagnocco A, Naredo E, Balint PV, Gutierrez M, Hammer HB, et al. OMERACT definitions for ultrasonographic pathologies and elementary lesions of rheumatic disorders 15 years on. J Rheumatol. 2019;46:1388-93.

34. Terslev L, Naredo E, Aegerter P, Wakefield RJ, Backhaus $\mathrm{M}$, Balint $\mathrm{P}$, et al. Scoring ultrasound synovitis in rheumatoid arthritis: a EULAR-OMERACT ultrasound taskforce-Part 2: reliability and application to multiple joints of a standardised consensus-based scoring system. RMD Open. 2017;3:e000427.

35. D'Agostino M-A, Terslev L, Aegerter P, Backhaus M, Balint P, Bruyn GA, et al. Scoring ultrasound synovitis in rheumatoid arthritis: a EULAR-OMERACT ultrasound taskforce-Part 1: definition and development of a standardised, consensus-based scoring system. RMD Open. 2017;3:e000428.

36. Girolimetto N, Zabotti A, Tinazzi I, Possemato N, Costa L, Batticciotto A, et al. Sensitivity to change and clinical correlations of the novel DACtylitis glObal Sonographic (DACTOS) score in psoriatic 
arthritis. Rheumatol (Oxf). 2020. https://doi.org/ 10.1093/rheumatology/keaa885.

37. Husted JA, Cook RJ, Farewell VT, Gladman DD. Methods for assessing responsiveness: a critical review and recommendations. J Clin Epidemiol USA. 2000;53:459-68.

38. Gossec L, Baraliakos X, Kerschbaumer A, de Wit M, McInnes I, Dougados $\mathrm{M}$, et al. EULAR recommendations for the management of psoriatic arthritis with pharmacological therapies: 2019 update. Ann Rheum Dis. 2020;79:700-12.

39. Di Geso L, Filippucci E, Meenagh G, Gutierrez M, Ciapetti A, Salaffi F, et al. CS injection of tenosynovitis in patients with chronic inflammatory arthritis: the role of US. Rheumatology (Oxford). 2012;51:1299-303.

40. Gutierrez M, Di Matteo A, Rosemffet M, Cazenave T, Rodriguez-Gil G, Diaz CH, et al. Short-term efficacy to conventional blind injection versus ultrasound-guided injection of local corticosteroids in tenosynovitis in patients with inflammatory chronic arthritis: a randomized comparative study. Joint Bone Spine. 2016;83:161-6.

41. Peters SE, Laxer RM, Connolly BL, Parra DA. Ultrasound-guided steroid tendon sheath injections in juvenile idiopathic arthritis: a 10-year single-center retrospective study. Pediatr Rheumatol Online J. 2017;15:22.
42. Ammitzbøll-Danielsen M, Østergaard M, Fana V, Glinatsi D, Døhn UM, Ørnbjerg LM, et al. Intramuscular versus ultrasound-guided intratenosynovial glucocorticoid injection for tenosynovitis in patients with rheumatoid arthritis: a randomised, double-blind, controlled study. Ann Rheum Dis. 2017;76:666-72.

43. Filippucci E, Farina A, Carotti M, Salaffi F, Grassi W. Grey scale and power Doppler sonographic changes induced by intra-articular steroid injection treatment. Ann Rheum Dis. 2004;63:740-3.

44. Dejaco C, Stadlmayr A, Duftner C, Trimmel V, Husic R, Krones E, et al. Ultrasound verified inflammation and structural damage in patients with hereditary haemochromatosis-related arthropathy. Arthritis Res Ther. 2017;19:243.

45. Pereira DF, Gutierrez $M$, de Buosi ALP, Ferreira FBMD, Draghessi A, Grassi W, et al. Is articular pain in rheumatoid arthritis correlated with ultrasound power Doppler findings? Clin Rheumatol. 2015;34: 1975-9.

46. Hirata A, Ogura T, Hayashi $\mathrm{N}$, Takenaka S, Ito $\mathrm{H}$, Mizushina $\mathrm{K}$, et al. Concordance of patient-reported joint symptoms, physician-examined arthritic signs, and ultrasound-detected synovitis in rheumatoid arthritis. Arthritis Care Res. 2017;69: 801-6. 